\title{
Shikonin causes apoptosis by disrupting intracellular calcium homeostasis and mitochondrial function in human hepatoma cells
}

\author{
HUI WANG ${ }^{1 *}$, ZHENG LIU $^{1 *}$, XIANGCHEN LI ${ }^{2}$, RUIJIE ZHAO ${ }^{2}$, \\ YABIN PU ${ }^{2}$, HANDONG WU ${ }^{1}$ and WEIJUN GUAN ${ }^{2}$ \\ ${ }^{1}$ Department of Food Nutrition, College of Food Science and Engineering, Jinzhou Medical University, \\ Jinzhou, Liaoning 121001; ${ }^{2}$ Department of Animal Genetic Resources, Institute of Animal Science, \\ Chinese Academy of Agricultural Sciences, Beijing 100193, P.R. China
}

Received August 3, 2017; Accepted October 27, 2017

DOI: $10.3892 /$ etm.2017.5591

\begin{abstract}
Shikonin is known to suppress proliferation and induce apoptosis in a variety of cancer cell lines. In the present study, SMMC-7721 human hepatocellular carcinoma cells were treated with shikonin $(1,2$ or $4 \mu \mathrm{M})$ for $12-48 \mathrm{~h}$. Cell morphological alterations and DNA damage were determined. Furthermore, changes in cell cycle, mitochondrial transmembrane potential, calcium homeostasis and levels of reactive oxygen species were measured. Shikonin-treated SMMC-7721 cells exhibited morphological changes and DNA damage. Shikonin inhibited cell proliferation causing cell cycle arrest at the $\mathrm{G}_{0} / \mathrm{G}_{1}$ phase and induced apoptosis in a dose- and time-dependent manner. Shikonin-induced apoptosis was associated with activation of caspases-3, -8 and -9 , elevated levels of intracellular $\mathrm{Ca}^{2+}$ and reactive oxygen species, reduced mitochondrial membrane potential and enhanced efflux of $\mathrm{Ca}^{2+}$ and $\mathrm{K}^{+}$. Gene expression B-cell lymphoma 2 (Bcl-2)-associated X protein (Bax), p53 and caspase-3 was up-regulated, whereas Bcl-2 expression was downregulated. Shikonin caused apoptosis by inhibiting cell cycle progression, disrupting $\mathrm{Ca}^{2+}$ homeostasis, inducing oxidative stress and triggering mitochondrial dysfunction. Activation of caspases-3, -8 and $-9, \mathrm{~K}^{+}$efflux, and regulation of $\mathrm{Bax}, \mathrm{Bcl}-2$,
\end{abstract}

Correspondence to: Professor Handong Wu, Department of Food Nutrition, College of Food Science and Engineering, Jinzhou Medical University, 40 Section 3 Songpo Road, Linghe, Jinzhou, Liaoning 121001, P.R. China

E-mail: wuhandongly@163.com

Professor Weijun Guan, Department of Animal Genetic Resources, Institute of Animal Science, Chinese Academy of Agricultural Sciences, 2 Yuanmingyuan West Road, Haidian, Beijing 100193, P.R. China

E-mail: guanweijun@outlook.com

${ }^{*}$ Contributed equally

Key words: human hepatocellular carcinoma, tumorigenesis, DNA damage, cell cycle progression, mitochondrial function p53 and caspase-3 expression are involved in the process. These results provide in-depth insight into the mechanisms of action of shikonin in the treatment of cancer.

\section{Introduction}

Human hepatocellular carcinoma (HCC) has a poor prognosis and is the fifth most frequent type of cancer and the third leading cause of cancer-associated mortalities globally, being accountable for $>600,000$ deaths per year (1). Despite monitoring efforts, most tumors, including HCC, are diagnosed in late stages. As uncontrolled cell proliferation and disrupted apoptosis are among the most important mechanisms underlying tumorigenesis, the focus of common tumor therapies is inhibition of cell division and induction of apoptosis. Apoptosis is the programmed cell death, regulated by numerous intra- and extracellular signals and governed by several genes, several of which are mutated or dysregulated in various human tumors (2). Drug-induced apoptosis of malignant cells is a promising anti-tumor strategy with emerging evidence supporting its effectiveness against hepatoma and other cancer types. However, currently available HCC therapies have proven unsatisfactory.

To reduce HCC mortality, development of efficient drugs with minimal cytotoxicity against normal, healthy cells is important. Traditional Chinese Medicine is a source of such compounds and is attracting increasing attention in cancer therapy.

Shikonin, whose chemical structure is displayed in Fig. 1A, is a natural naphthoquinone isolated from the traditional Chinese medical herb Zi Cao (Lithospermum erythrorhizon, Siebold \& Zucc. of the Boraginaceae family, also known as purple gromwell), which has been used as an herbal medicine in East Asia for centuries (3). It has anti-tumor, anti-oxidant, anti-bacterial, antiangiogenic and anti-inflammatory properties (4). The anti-tumor activity of shikonin has been demonstrated in various cancer cell lines (5-7). The anti-tumor potential of shikonin is associated with inhibition of malignant cell growth and induction of cancer cell apoptosis by intracellular oxidative stress $(8,9)$, as well as caspase-3-dependent apoptosis, topoisomerase-mediated DNA cleavage and cell cycle arrest (10). Shikonin accumulates in mitochondria and deregulates cellular $\mathrm{Ca}^{2+}$ and the level of reactive oxygen 
species (ROS), leading to breakdown of the mitochondrial membrane (11). In addition, shikonin inhibits cancer cell proliferation, as well as glucose and lactate metabolism by targeting tumor pyruvate kinase M2 (12).

Several cellular processes have been implicated in the anti-cancer effects of shikonin; however, the precise underlying mechanisms remain elusive and require further research. The SMMC-7721 hepatoma cell line is primarily used for drug screening and investigation of apoptotic mechanisms. The present study investigated the antitumor effects of shikonin in the SMMC-7721 hepatoma cell line, focusing on apoptotic effects, cell proliferation, DNA damage, mitochondrial function, calcium and potassium homeostasis, caspase activity and gene expression. Understanding the underlying mechanisms of shikonin's anti-tumor potential may provide an experimental foundation for the clinical use of shikonin in the treatment of hepatocellular carcinoma.

\section{Materials and methods}

Materials. Shikonin (98\% purity), MTT, acridine orange (AO) and ethidium bromide (EB) were purchased from Sigma-Aldrich (Merck KGaA, Darmstadt, Germany). Propidium iodide (PI), Dulbecco's modified Eagle's medium (DMEM) and fetal bovine serum (FBS) were from Gibco Gibco (Thermo Fisher Scientific, Inc., Waltham, MA, USA). The Annexin V-FITC Apoptosis Detection kit I was purchased from BD Biosciences (Franklin Lakes, NJ, USA). Fluo3-AM was from Thermo Fisher Scientific, Inc.

Cell culture. The SMMC-7721 human hepatoma cell line was obtained from the Institute of Biochemistry and Cell Biology, Chinese Academy of Sciences (Shanghai, China). The SMMC-7721 cells were cultured in high-glucose DMEM supplemented with $10 \% \mathrm{FBS}$ at $37^{\circ} \mathrm{C}$ in a humidified incubator with $5 \% \mathrm{CO}_{2}$. The culture medium was changed every 2-3 days.

Shikonin treatment. Shikonin was dissolved in dimethyl sulfoxide (DMSO) to generate a 4-mM stock solution (stored at $-20^{\circ} \mathrm{C}$ ) and subsequently diluted in culture medium to the final concentration used in each experiment. The final concentration of DMSO was $0.1 \%$. Controls were treated with an equivalent amount of DMSO. Cells were in the logarithmic phase when treated with shikonin $(0,1,2$ or $4 \mu \mathrm{M})$ for predetermined periods (12, 24, 36 and $48 \mathrm{~h})$.

Cell viability assay. Cell viability was analyzed using the MTT assay. Cell suspensions $(200 \mu \mathrm{l})$ were seeded in 96-well plates at a density of $1 \times 10^{5}$ cells/well. Cells in the logarithmic phase were exposed to $180 \mu \mathrm{l}$ fresh complete medium containing different concentrations of shikonin. MTT $(20 \mathrm{ml}, 5 \mathrm{mg} / \mathrm{ml})$ was added, and the cells were incubated for another $4 \mathrm{~h}$. After discarding the supernatant, the precipitate was dissolved in DMSO $(200 \mu \mathrm{l})$ and the absorbance was measured at $490 \mathrm{~nm}$ using a microplate reader (Elx 800; BioTek Instruments, Winooski, VT, USA).

DNA fragmentation assay. In brief, cells were harvested, lysed with $200 \mu \mathrm{l}$ lysis buffer (1 mM EDTA, 0.2\% Triton X-100 and $10 \mathrm{mM}$ Tris-HCl, pH 7.5) and centrifuged at $12,000 \mathrm{x}$ and $4^{\circ} \mathrm{C}$ for $5 \mathrm{~min}$, the supernatant for further used. DNA samples were precipitated in $12.5 \%$ trichloroacetic acid (TCA) and quantified using diphenylamine after hydrolysis in 5\% TCA, the fragmented and total DNA was measured with a spectrophotometer (ND-1000; NanoDrop Technologies, Wilmington, NC, USA). The DNA samples were electrophoresed on $2 \%$ agarose gel and visualized under UV light with ethidium bromide.

Morphological observation. Cells were seeded in 6-well plates at a density of $1 \times 10^{5}$ cells/well, when cells were in the logarithmic phase, they were treated with shikonin $(1,2$ and $4 \mu \mathrm{M})$ at $37^{\circ} \mathrm{C}$ for $24 \mathrm{~h}$, and then examined under a phase contrast microscope at a magnification of $\mathrm{x} 100$.

Transmission electron microscopy (TEM). Cells were collected, fixed with $2.5 \%(\mathrm{~m} / \mathrm{v})$ glutaraldehyde and washed with $0.1 \mathrm{~mol} / \mathrm{l}$ PBS prior to serial dehydration with $30,50,70,80,90$ and $100 \%$ acetone (v/v). The samples were embedded with epoxy resin (Spurr) for polymerization, sliced with an ultramicrotome (LEICAUC6i), and stained with uranyl acetate and lead citrate prior to TEM analysis (JEM-2000Ex; JEOL Ltd., Tokyo, Japan).

$A O / E B$ double staining. Cells were treated with 1,2 or $4 \mu \mathrm{M}$ shikonin for $24 \mathrm{~h}$, after which cell suspensions were harvested and stained with $\mathrm{AO}$ and $\mathrm{EB}$ solutions (both $\mathrm{AO}$ and $\mathrm{EB}$ in ethanol, the respective concentration was $2 \mathrm{mg} / \mathrm{ml}$ ). After incubation at $25^{\circ} \mathrm{C}$ in the dark for $5 \mathrm{~min}$, the samples were observed using confocal microscopy (Nikon TE-2000-E; Nikon, Tokyo, Japan).

Terminal deoxynucleotidyl transferase-mediated deoxyuridine triphosphate nick end labeling (TUNEL) assay. The TUNEL assay was performed as previously described (13). In brief, cells were stained with TUNEL reagent (Roche Diagnostics, Basel, Switzerland), and the number of TUNEL-positive cells was counted in 20 randomly selected microscopic fields at 40x magnification.

Annexin V-fluorescein isothiocyanate (FITC)/PI doublelabeling. Apoptosis was evaluated using the Annexin V-FITC Apoptosis Detection kit per the manufacturer's instructions. In brief, cells were stained with FITC and PI and analyzed via flow cytometry (BD FACSCalibur; BD Biosciences) to detect early (FITC-positive and PI-negative) and late (FITC- and PI-positive) apoptotic cells.

Cell cycle analysis. To estimate the proportion of cells in different phases of the cell cycle and the apoptotic effects of shikonin, cell DNA contents were analyzed using flow cytometry. Cell samples were harvested by centrifugation, gently fixed with $70 \%$ ethanol on ice overnight and stained with PI solution (0.05 mg/ml PI, $0.02 \mathrm{mg} / \mathrm{ml}$ RNase, $0.585 \mathrm{~g} / \mathrm{ml} \mathrm{NaCl}, 1 \mathrm{mg} / \mathrm{ml}$ sodium citrate, $\mathrm{pH} 7.2-7.6$ ) in the dark for $15 \mathrm{~min}$. The cells were analyzed by flow cytometry (BD FACSCalibur).

Analysis of mitochondrial membrane potential. The cells were collected and washed twice with prewarmed PBS, and adjusted to the concentration of $1 \times 10^{6}$ cells/sample. After the addition of JC-1 working solution ( $5 \mu \mathrm{g} / \mathrm{ml}, 0.5 \mathrm{ml} / \mathrm{sample})$, the cells were incubated at $37^{\circ} \mathrm{C}$ in the dark for $10 \mathrm{~min}$ and washed twice with prewarmed PBS. After centrifugation at $1,000 \times \mathrm{g}\left(25^{\circ} \mathrm{C}\right.$ 
for $5 \mathrm{~min}$ ), the supernatant was discarded. Samples were resuspended with $0.5 \mathrm{ml}$ PBS and analyzed using flow cytometry (BD FACSCalibur).

Analysis of intracellular calcium homeostasis. Cells were collected and the concentration adjusted to $2 \times 10^{6}$ cells $/ \mathrm{ml}$ prior to loading with Fluo3-AM, final concentration, $6 \mu \mathrm{M}$; (stock solution of Fluo3-AM was $2 \mathrm{mM}, 1 \mathrm{mg}$ Fluo3-AM was dissolved in $442 \mu \mathrm{l}$ DMSO). Cells were incubated at $37^{\circ} \mathrm{C}$ with $5 \% \mathrm{CO}_{2}$ in the dark for $40 \mathrm{~min}$ and then resuspended in $0.5 \mathrm{ml}$ calcium-free PBS prior to analysis using flow cytometry (BD FACSCalibur).

Extracellular $\mathrm{Ca}^{2+}$ and $\mathrm{K}^{+}$flux measurements. A microelectrode ion flux estimation (MIFE) technique was used to monitor $\mathrm{Ca}^{2+}$ and $\mathrm{K}^{+}$flux during shikonin-induced apoptosis in SMMC-7721 human hepatoma cells, as previously described (14).

ROS measurement. Cells $\left(2 \times 10^{6} / \mathrm{ml}\right)$ were loaded with 2',7'-dichlorodihydrofluorescein diacetate (DCFH-DA; Molecular Probes, Eugene, OR, USA) at a final concentration of $8 \mu \mathrm{M}$, incubated at $37^{\circ} \mathrm{C}$ with $5 \% \mathrm{CO}_{2}$ for $30 \mathrm{~min}$, washed and analyzed using flow cytometry (FC500; Beckman Coulter, Brea, CA, USA). At least 10,000 events were analyzed at excitation and emission wavelengths of 488 and $525 \mathrm{~nm}$, respectively.

Caspase activity assay. Activities of caspase- $3,-8$ and -9 were evaluated using a caspase activity kit (Beyotime Institute of Biotechnology, Haimen, China) per the manufacturer's instructions and as previously described (15).

Semi-quantitative reverse transcription-polymerase chain reaction $(R T-P C R)$. Total RNA was extracted from cultured cells and used to synthesize the first complementary DNA (cDNA) strand using the PrimerScript RT reagent kit (Takara, Dalian, China) per the manufacturer's instructions. Specific primers for B-cell lymphoma 2 (Bcl-2), Bcl-2-associated X protein (Bax), caspase-3, p53 and GAPDH (housekeeping gene used as an internal control) were designed by Primer Premier 5.0 software and synthesized by Shanghai Biotechnology Co.,Ltd. (Shanghai, China). Primer sequences are listed in Table I. Composition of the PCR mixture is listed in Table II. PCR conditions were as follows: Denaturation at $94^{\circ} \mathrm{C}$ for $5 \mathrm{~min}, 32$ cycles of denaturation at $94^{\circ} \mathrm{C}$ for $30 \mathrm{sec}$, annealing for $30 \mathrm{sec}$ at $52-55^{\circ} \mathrm{C}$ and elongation at $72^{\circ} \mathrm{C}$ for $30 \mathrm{sec}$, and a final elongation at $72^{\circ} \mathrm{C}$ for $10 \mathrm{~min}$. PCR products were identified by gel electrophoresis on $1.5 \%$ agarose as previously described (16).

Statistical analysis. Assays were performed in triplicates of three independent experiments. Values are expressed as the mean \pm standard deviation. Data were analyzed using Statistical Analysis System (SAS) software (SAS Institute Inc., Cary, NC, USA) and compared using 2-tailed Student's t-test. $\mathrm{P}<0.05$ was considered to indicate a statistically significant difference.

\section{Results}

Shikonin reduces the viability of hepatocellular carcinoma cells. SMMC-7721 cell viability was evaluated using the MTT assay following exposure to increasing concentrations of shikonin $(0-4 \mu \mathrm{M})$ for $12,24,36$ or $48 \mathrm{~h}$. The population of viable cells decreased significantly with increasing shikonin concentrations and duration of treatment in a dose- and time-dependent manner (Fig. 1B). These results suggested that shikonin is an effective inhibitor of SMMC-7721 cell proliferation.

DNA fragmentation assay. Agarose gel electrophoresis of SMMC-7721 cell samples at $24 \mathrm{~h}$ after shikonin treatment revealed a DNA ladder, indicating DNA fragmentation and demonstrating that shikonin damages the DNA and is a DNA-binding agent with cytotoxic activity on SMMC-7721 cells (Fig. 1C).

Morphological observation. Under normal circumstances, adherent cells are elliptical. During the logarithmic growth phase, passaged cells gradually adhere and grow. In the present study, control cells were closely arranged, with a uniform size, as well as good vitality and refractivity (Fig. 1D). Shikonin-treated cells displayed atrophy and vacuoles, shrinkage of the cytoplasm, decreased cell number, cell fragmentation, blurred contours, and reduced cell connections; certain cells were lysed into small pieces. Apoptotic cells detached from adjacent normal cells, displaying obvious differences in morphology (Fig. 1D).

TEM. The effects of shikonin on the microstructure of SMMC-7721 cells were assessed using TEM (Fig. 1E). Cells in the control group displayed a homogenous cytoplasm, microvilli on the cell surface, large, round nuclei with intact nuclear membrane and subcellular structures, clear and regular nucleoli, and loose chromatin. Cells in the treatment group exhibited vesiculation of cytoplasmic organelles, membrane blebbing, pyknosis, fragmentation, shrinkage or disappearance of the nucleus, cytoskeletal degradation, rupture of the plasma and nuclear membrane and reduced microvilli on the cell surface.

$A O / E B$ double staining. $\mathrm{AO}$ and $\mathrm{EB}$ differ in permeability and fluorescence, distinguished cells in early (yellow) and late apoptosis (orange fluorescence), as well as cells that were normal (green) and necrotic (red). AO/EB double staining demonstrated that shikonin caused apoptosis of SMMC-7721 cells in a dose-dependent manner (Fig. 1F).

TUNEL assay. Shikonin treatment for $24 \mathrm{~h}$ triggered apoptosis in SMMC 7721 cells in a dose-dependent manner as determined by the TUNEL assay (Fig. 1G).

Annexin V-FITC/PI double-staining. The apoptotic effects of shikonin on SMMC-7721 cells were quantified using flow cytometry after Annexin V-FITC/PI staining, which is based on phosphatidylserine externalization. Shikonin was demonstrated to exert dose- and time-dependent apoptotic effects (Fig. 2A and B).

Shikonin inhibits the cell cycle of hepatocellular carcinoma cells. Shikonin treatment resulted in a dose-dependent accumulation of cells in the $G_{0} / G_{1}$ phase of the cell cycle, with a concomitant decrease in the proportion of cells in the $\mathrm{S}$ phase (Fig. $2 \mathrm{C}$ and D), indicating cell cycle arrest in $\mathrm{G}_{1}$ phase. A dose-dependent increase in the proportion of apoptotic cells in the hypodiploid DNA peak (sub- $\mathrm{G}_{1}$ population) was identified (Fig. 2C and D). 
Table I. Primer sequences of apoptosis-associated genes and their melting temperatures.

\begin{tabular}{|c|c|c|c|}
\hline Gene & Primer & Length (bp) & $\operatorname{Tm}\left({ }^{\circ} \mathrm{C}\right)$ \\
\hline GAPDH & $\begin{array}{l}\text { F, 5'-AGAAGGCTGGGGGCTCATTTG-3' } \\
\text { R, 5'-AGGGGCCATCCACAGTCTTC-3' }\end{array}$ & 258 & 55 \\
\hline Bax & $\begin{array}{l}\text { F, 5'-CAGGATGCGTCCACCAAGAA-3' } \\
\text { R, 5'-GTGTCCCGAAGGAGGTTTATT-3' }\end{array}$ & 765 & 55 \\
\hline Bcl-2 & $\begin{array}{l}\text { F, 5'-TGGGAGAACAGGGTACGATAA-3' } \\
\text { R, 5'-ACAGCCAGGAGAAATCAAACA-3' }\end{array}$ & 275 & 53 \\
\hline Fas & $\begin{array}{l}\text { F, 5'-CGCTTCTGGGGAGTGAGGGA-3' } \\
\text { R, 5'-GGTGTTGCTGGTGAGTGTGC-3' }\end{array}$ & 454 & 52 \\
\hline P53 & $\begin{array}{l}\text { F, 5'-AGGGGAGACCAGAACCTCTC-3' } \\
\text { R, 5'-GCACCACCTTCCTTCCAAAA-3' }\end{array}$ & 661 & 55 \\
\hline Caspase-3 & $\begin{array}{l}\text { F, 5'-GAAGAACTTAGGCATCTGTGGGC-3' } \\
\text { R, 5'-GTATGGAGAAATGGGCTGTAGGC-3' }\end{array}$ & 661 & 55 \\
\hline
\end{tabular}

F, forward; R, reverse; bp, base pairs; Tm, melting temperature; Bcl-2, B-cell lymphoma 2; Bax, Bcl-2-associated X protein.

Shikonin reduces the mitochondrial membrane potential of hepatocellular carcinoma cells. To observe changes in mitochondrial membrane potential after shikonin treatment, cells were stained with JC-1 and examined using flow cytometry. JC-1 is a lipophilic, cationic dye that selectively enters mitochondria and reversibly changes color from green to red as the membrane potential increases. The JC-1 dye aggregates and fluoresces red in normal cells, whereas at a low mitochondrial membrane potential, JC-1 monomers fluoresce green. Reduced red fluorescence and increased green fluorescence in shikonin-treated cells, compared to the control group, indicated a reduced mitochondrial membrane potential (Fig. 3A and B).

Shikonin affects intracellular $\mathrm{Ca}^{2+}$ homeostasis. Intracytoplasmic esterases hydrolyze Fluo3-AM into Fluo3, which binds to intracytoplasmic free $\mathrm{Ca}^{2+}$ to form Fluo3-Ca ${ }^{2+}$ complexes. The $\mathrm{Ca}^{2+}$ concentration in shikonin-treated cells was significantly higher than that in control cells, indicating a positive association between $\mathrm{Ca}^{2+}$ release and shikonin treatment (Fig. 3C and D).

Shikonin increases extracellular $\mathrm{Ca}^{2+}$ and $\mathrm{K}^{+}$flux. Extracellular $\mathrm{Ca}^{2+}$ and $\mathrm{K}^{+}$flux prior to and after shikonin treatment $(4 \mu \mathrm{M})$ in SMMC-7721 cells was monitored using the MIFE method (Fig. 3E and F). The results indicated that the efflux of $\mathrm{Ca}^{2+}$ and $\mathrm{K}^{+}$increased after shikonin treatment.

Shikonin increases ROS in hepatocellular carcinoma cells. DCFH-DA is hydrolyzed by cellular esterases to form the nonfluorescent DCFH, which is then oxidized by a variety of ROS to form the highly fluorescent DCF. DCFH-DA staining was used to determine whether ROS have a role in shikonin-induced apoptosis in SMMC-7721 cells. Shikonin treatment significantly and dose-dependently enhanced ROS production in SMMC-7721 cells (Fig. 4A).

Shikonin causes caspase activation in hepatocellular carcinoma cells. To elucidate the mechanisms of shikonin-induced
Table II. Composition of the polymerase chain reaction mixture.

\begin{tabular}{lr} 
Components & Volume $(\mu l)$ \\
\hline Takara Ex-Taq & 0.25 \\
10X Ex-Taq Buffer & 5 \\
dNTP $(2.5 \mathrm{mM})$ & 4 \\
cDNA & 2 \\
Primer $(\mathrm{F}, 10 \mu \mathrm{M})$ & 2 \\
Primer $(\mathrm{R}, 10 \mu \mathrm{M})$ & 2 \\
ddH $_{2} \mathrm{O}$ & 35 \\
Total & 50
\end{tabular}

F, forward; R, reverse.

apoptosis in SMMC-7721 cells, the activation of caspase-3, -8 and -9 was monitored. Caspase-3 and -9 activities in the 2- and 4- $\mu \mathrm{M}$ shikonin treatment groups were significantly higher than those in the controls $(\mathrm{P}<0.01)$, as was caspase- 8 activity in the $4 \mu \mathrm{M}$ shikonin treatment group $(\mathrm{P}<0.01$; Fig. 4B). Collectively, these results indicate that shikonin activates caspases-3, -8 and -9 in SMMC-7721 cells.

Shikonin induces the expression of apoptotic genes. Bax, Bcl-2, p53 and caspase-3 mRNA expression levels were determined using RT-PCR to assess the involvement of corresponding proteins in shikonin-mediated apoptosis. Exposure of SMMC-7721 cells to shikonin significantly increased Bax, p53 and caspase-3 gene expression $(\mathrm{P}<0.01)$ and significantly decreased $\mathrm{Bcl}-2$ gene expression $(\mathrm{P}<0.01)$, resulting in an increase in the Bax/Bcl-2 ratio (Fig. $4 \mathrm{C}$ and D).

\section{Discussion}

Growth inhibition and induction of apoptosis are two key mechanisms by which chemotherapeutic agents induce 
A<smiles>CC(C)=CCC(O)C1CC(=O)c2c(O)ccc(O)c2C1=O</smiles>

B $2.5[-$ Control $\square 1 \mu \mathrm{M} \square 2 \mu \mathrm{M} \square 4 \mu \mathrm{M}$

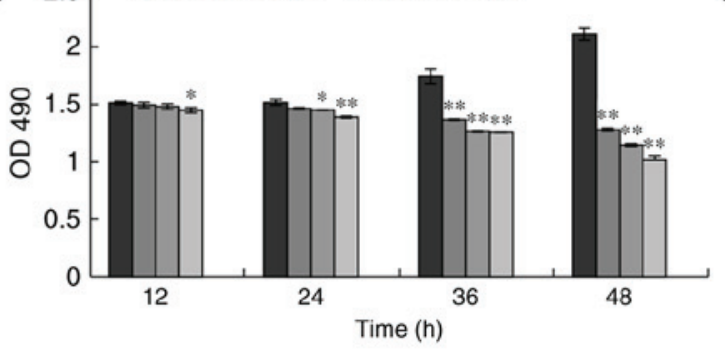

C

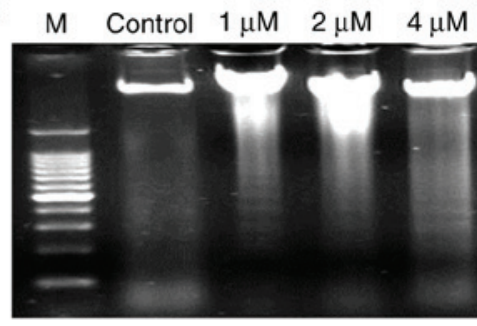

D

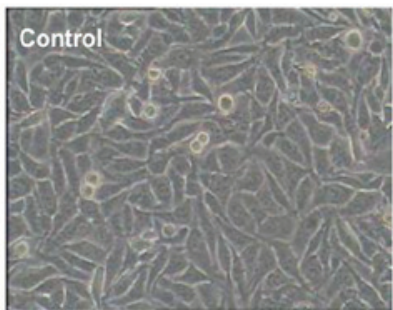

E

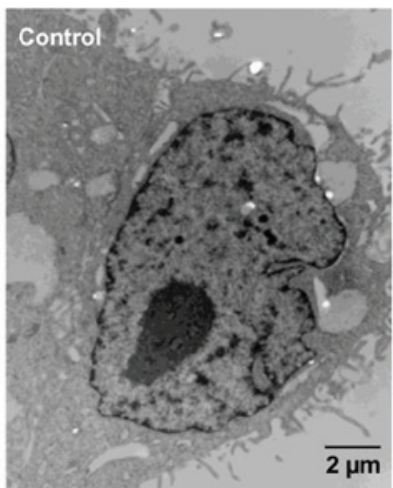

$\mathrm{F}$

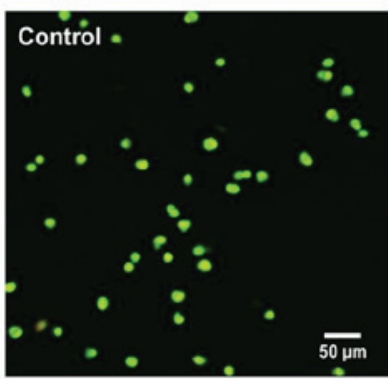

G

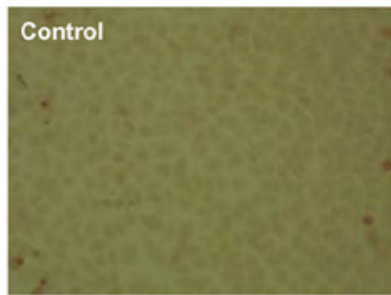

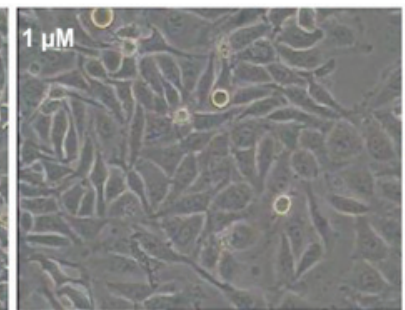
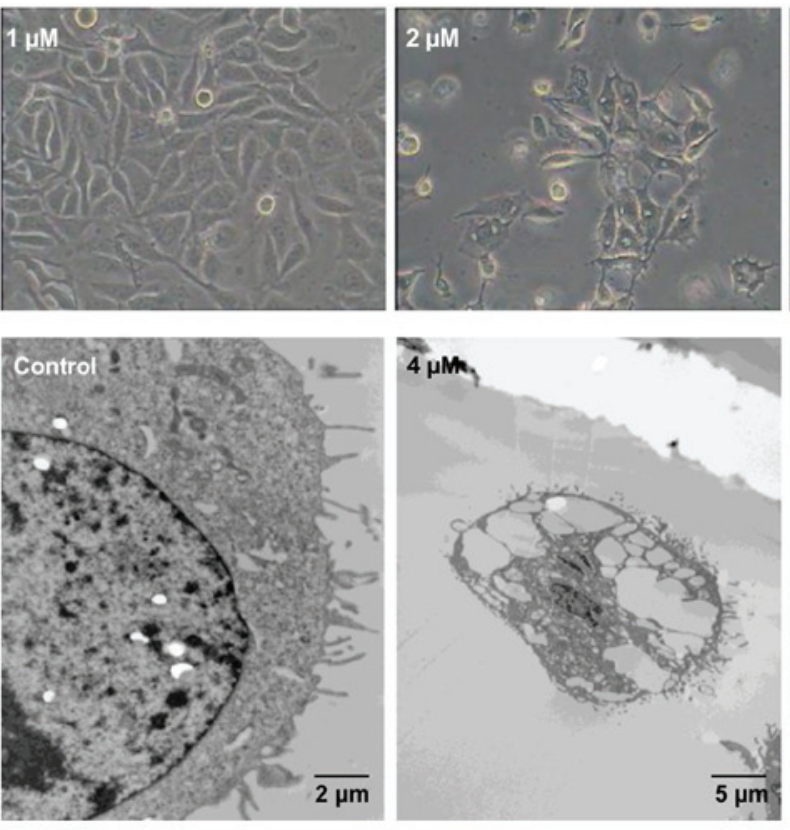

$4 \mu \mathrm{M}$
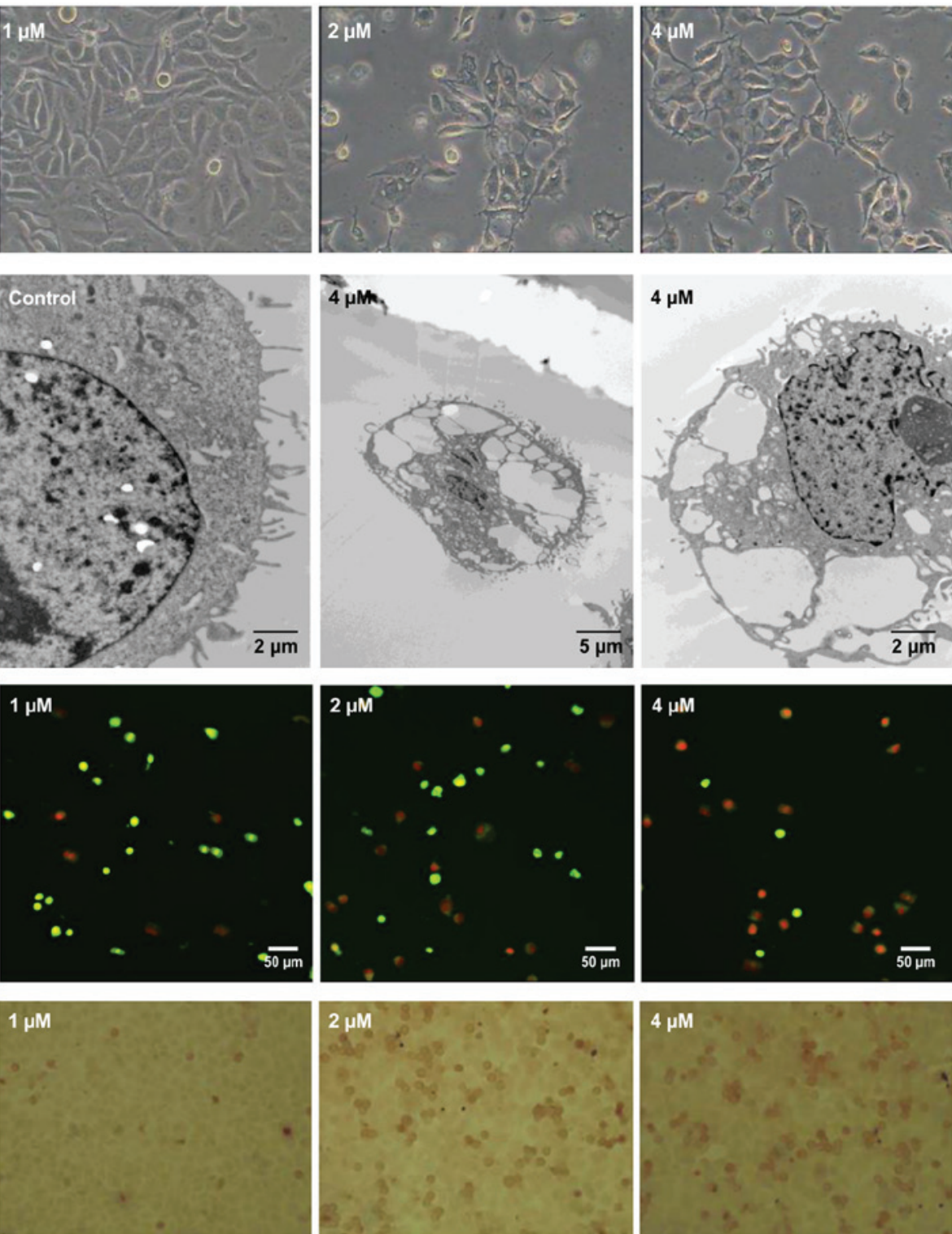

Figure 1. Apoptotic effects of shikonin on SMMC-7721 cells. (A) Chemical structure of shikonin. (B) Cytotoxicity analysis via the MTT assay. Values are expressed as the mean \pm standard deviation of three independent experiments. ${ }^{*} \mathrm{P}<0.05,{ }^{* *} \mathrm{P}<0.01$ vs. corresponding control. (C) DNA fragmentation analysis of cells treated with shikonin for $24 \mathrm{~h}$. (D) Morphological changes of SMMC-7721 cells treated with shikonin for $24 \mathrm{~h}$ (magnification, x100). (E) Transmission electron microscopy images of changes in subcellular structures after $24 \mathrm{~h}$ (scale bar, 2 or $5 \mu \mathrm{m}$ ). (F) Morphological observation of nuclear damage in SMMC-7721 cells after $24 \mathrm{~h}$ (scale bar, $50 \mu \mathrm{m}$ ). (G) Apoptosis analysis of cells treated with shikonin for $24 \mathrm{~h}$ using a terminal deoxynucleotidyl transferase deoxyuridine triphosphate nick-end labeling assay (magnification, x40). OD 490, optical density at $490 \mathrm{~nm}$; M, marker.

cytotoxic effects in cancer cells (17). Therefore, chemical agents with potent differentiation- or apoptosis-inducing activity and acceptable toxicity have potential as anticancer drugs. Shikonin inhibits cell proliferation and induces apoptosis in various human cancer cell types (18). Induction of apoptosis is associated with caspases (19), the Bcl-2 family (4) and mitogen-activated protein kinase (20). Furthermore, shikonin has been reported to induce autophagy in the BEL7402 and Huh7 human hepatocellular carcinoma cell lines (21).

In the present study, shikonin caused typical apoptosisassociated morphological changes and DNA fragmentation, 
A
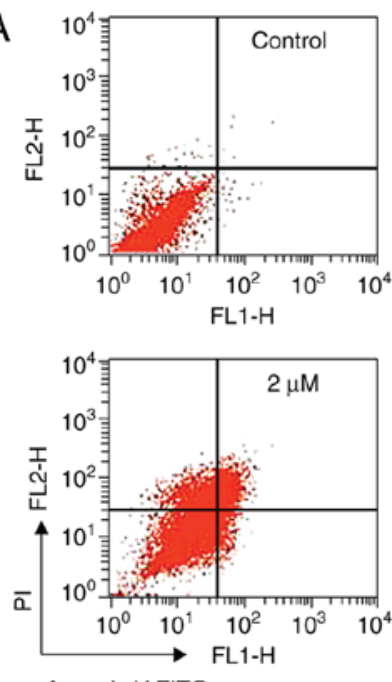

Annexin V-FITC
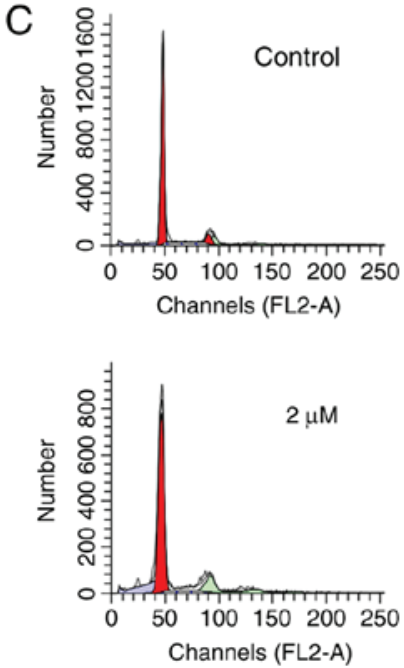
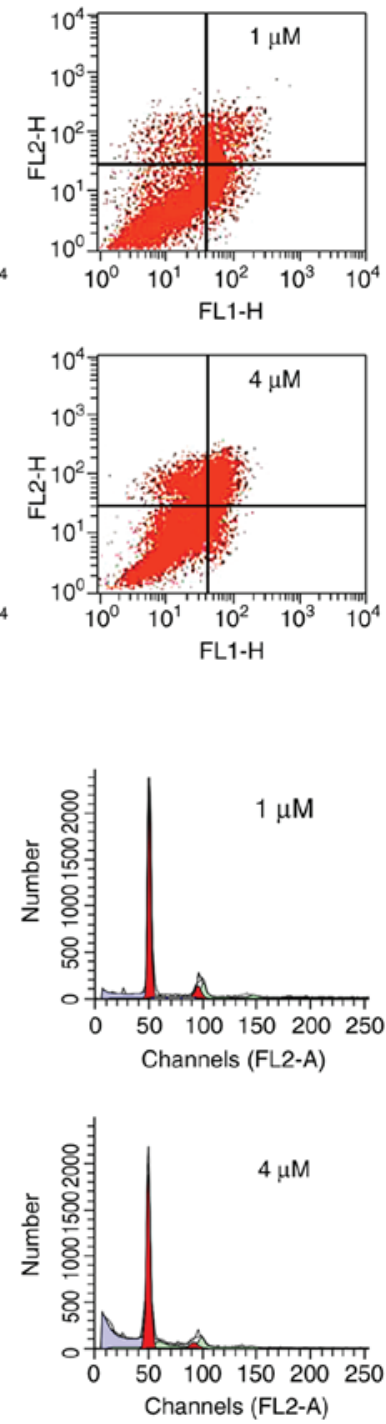
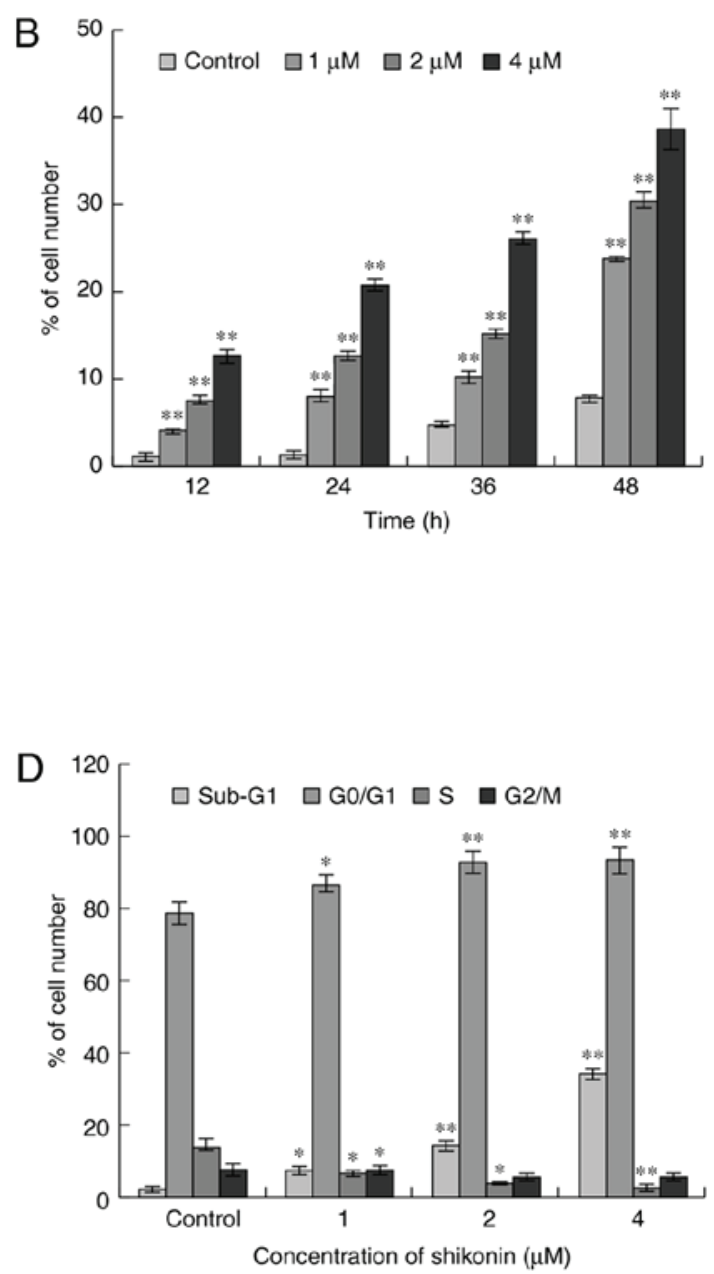

Figure 2. Effect of shikonin on apoptotic rates and cell cycle. (A) Apoptotic rates of SMMC-7721 cells treated with shikonin for $24 \mathrm{~h}$ (scatter plot data at 12 , 36 and 48 h not shown). (B) Apoptotic rates of SMMC-7721 cells treated with shikonin for 12, 24, 36 and 48 h. (C) Cell cycle progression and sub-G 1 content

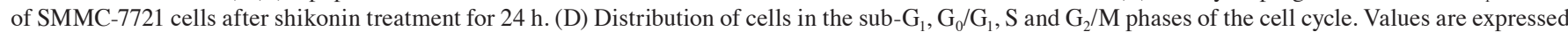
as the mean \pm standard deviation of three independent experiments. ${ }^{*} \mathrm{P}<0.05,{ }^{* *} \mathrm{P}<0.01$ vs. corresponding control. PI, propidium iodide; FITC, fluorescein isothiocyanate.

inhibited cell proliferation and induced apoptosis of SMMC-7721 cells in a dose- and time-dependent manner. It was further demonstrated that shikonin induces apoptosis of SMMC-7721 cells associated with increased caspase activity and ROS generation, mitochondrial dysfunction, $\mathrm{K}^{+}$efflux, disturbed $\mathrm{Ca}^{2+}$ homeostasis and altered Bax, Bcl-2, p53 and caspase- 3 gene expression.

Physiological or pathological apoptotic stimuli are correlated with cell cycle progression. In the present study, it was demonstrated that shikonin inhibits cell proliferation by inducing apoptosis and $\mathrm{G}_{0} / \mathrm{G}_{1}$ phase arrest of SMMC-7721 cells in vitro. Shikonin caused a dose- and time-dependent loss of plasma membrane integrity, as indicated by the increased proportion of PI-stained cells. In addition, shikonin-treated cells exhibited apoptotic DNA fragmentation and dose-dependent increases in the sub- $\mathrm{G}_{1}$ cell population, in agreement with the TUNEL assay results. The anti-proliferative effects of shikonin associated with the induction of cell cycle arrest in $G_{0} / G_{1}$ phase were previously reported for various cancer cell lines $(11,22)$. However, shikonin-induced $\mathrm{G}_{2} / \mathrm{M}$ cell cycle arrest was reported in Ewing sarcoma cells (23). Induction of cell cycle arrest in different cell cycle phases under different biological conditions and simultaneous cell cycle arrest at two checkpoints have been previously described $(24,25)$. Further research is required to elucidate shikonin-induced cell cycle arrest and the factors associated with it.

Decreased mitochondrial membrane potential is a relatively early event of apoptotic signaling, occurring prior to nuclear apoptotic changes. The importance of mitochondria for apoptosis is well recognized (26). Shikonin induced a decrease in mitochondrial membrane potential that correlated with the loss of plasma membrane integrity. Shikonin treatment was previously demonstrated to lead to apoptosis of cells characterized by reduced mitochondrial membrane potential and positive PI staining (27). Decreased mitochondrial membrane potential was also observed in shikonin-treated human SK-Hep-1 cells (28) and HepG2 cells (29). In the present study, the decreased mitochondrial membrane potential detected by JC-1 
A
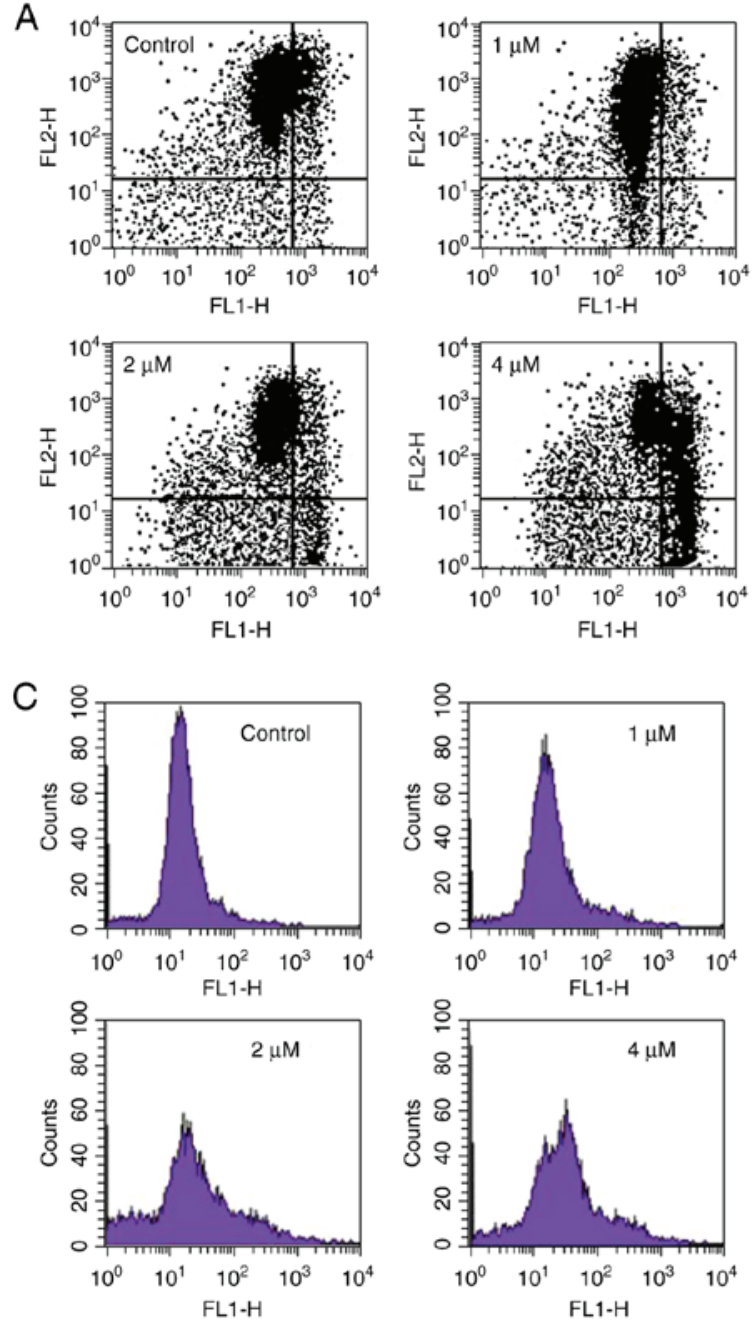

$\mathrm{E}$

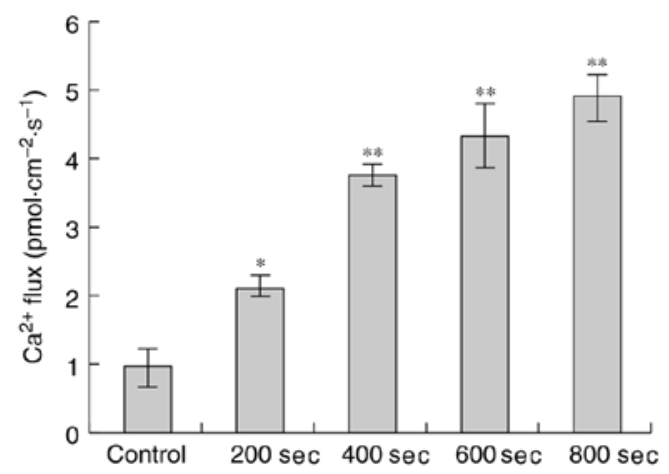

B
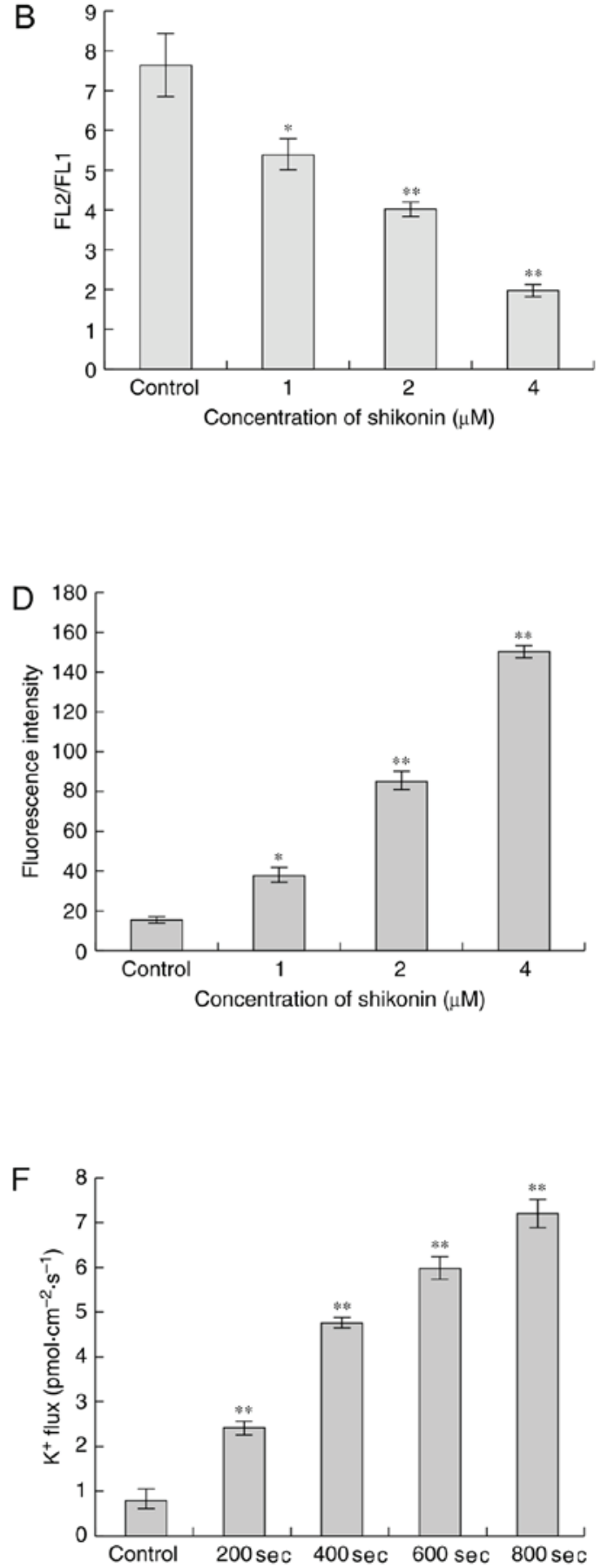

Figure 3. Effect of shikonin on cell mitochondrial and intracellular $\mathrm{Ca}^{2+}$. (A and B) Mitochondrial membrane potential of SMMC-7721 cells at $24 \mathrm{~h}$ after treatment with shikonin. ( $\mathrm{C}$ and D) Intracellular $\mathrm{Ca}^{2+}$ homoeostasis of SMMC-7721 cells treated with shikonin for $24 \mathrm{~h}$. A rightward-moving peak indicates an increase in intracellular free $\mathrm{Ca}^{2+}$. (E) $\mathrm{Ca}^{2+}$ flux and (F) $\mathrm{K}^{+}$flux in SMMC-7721 cells prior to and after treatment with $4 \mu \mathrm{M}$ shikonin. Values are expressed as the mean \pm standard deviation of three independent experiments. ${ }^{*} \mathrm{P}<0.05,{ }^{* *} \mathrm{P}<0.01$ vs. corresponding control.

staining confirmed the association between mitochondrial dysfunction and shikonin-induced apoptosis.

Shikonin was reported to induce ROS generation and subsequently trigger apoptosis in human HCC cells (1). It also enhanced ROS generation in chronic myelogenous leukemia (8), osteosarcoma cells (30) and human liver cancer cells, including the HepG2 hepatoblastoma, as well as the Huh7 and BEL7402 hepatocellular carcinoma cell lines (1). The results of the present study indicated that shikonin increases ROS generation in a dose-dependent manner, triggering mitochondrial dysfunction.
The release of $\mathrm{Ca}^{2+}$ from the endoplasmic reticulum into the cytoplasm is a key signaling event, sensitizing mitochondria in numerous models of apoptosis (31). Mitochondrial calcium overload leads to mitochondrial damage, release of cytochrome $c$, activation of caspases and subsequent apoptosis (32). The present results indicated that during shikonin-induced apoptosis of SMMC-7721 cells, the free cytosolic $\mathrm{Ca}^{2+}$ concentration increased, disturbing $\mathrm{Ca}^{2+}$ homeostasis. Disturbed $\mathrm{Ca}^{2+}$ homeostasis, combined with a decrease in mitochondrial membrane potential, implies that 

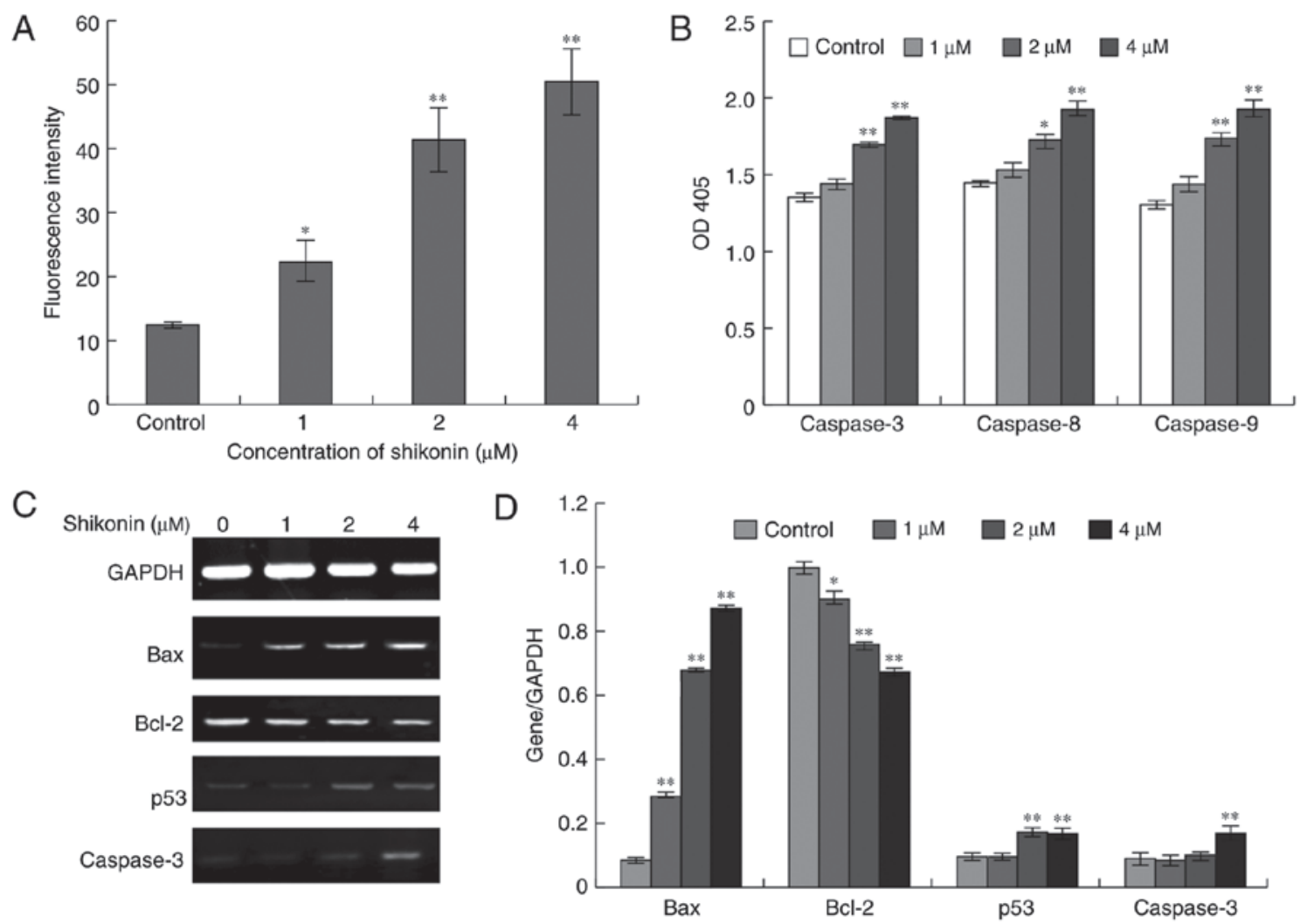

Figure 4. Analysis of shikonin-induced apoptosis of SMMC-7721 cells. (A) Generation of intracellular reactive oxygen species in SMMC-7721 cells treated with shikonin for $24 \mathrm{~h}$. (B) Caspase-3, -8, and -9 activities were determined in cytosolic extracts of SMMC-7721 cells at $24 \mathrm{~h}$ after treatment with shikonin. (C and D) Analysis of Bax, Bcl-2, p53 and caspase-3 mRNA expression levels at $24 \mathrm{~h}$ (normalized to GAPDH). Values are expressed as the mean \pm standard deviation of three independent experiments. ${ }^{*} \mathrm{P}<0.05,{ }^{* *} \mathrm{P}<0.01$ vs. corresponding control. OD 405 , optical density at $405 \mathrm{~nm}$; Bcl-2, B-cell lymphoma 2 ; Bax, Bcl-2-associated X protein.

$\mathrm{Ca}^{2+}$ is released from the endoplasmic reticulum and mitochondria. $\mathrm{Ca}^{2+}$ release from intracellular calcium stores and extracellular $\mathrm{Ca}^{2+}$ influx are two possible causes of an increase in intracellular free $\mathrm{Ca}^{2+}$. The present analysis of $\mathrm{Ca}^{2+}$ flux indicated that in the presence of shikonin the flow rate of the $\mathrm{Ca}^{2+}$ efflux increased with time. These results implied that the increase in intracellular free $\mathrm{Ca}^{2+}$ was caused by a release of endogenous $\mathrm{Ca}^{2+}$ stores rather than the absorption of extracellular $\mathrm{Ca}^{2+}$.

Loss of intracellular $\mathrm{K}^{+}$is a characteristic of apoptosis, alongside cell shrinkage, nuclear condensation, DNA fragmentation and formation of apoptotic bodies (33). In the present $\mathrm{K}^{+}$flux analysis, efflux was observed prior to and after treatment, with the flow rate increasing with time. $\mathrm{K}^{+}$efflux has been documented in the early stages of apoptosis, with high extracellular $\mathrm{K}^{+}$concentrations and $\mathrm{K}^{+}$channel blockers inhibiting the process (34).

Shikonin has been reported to trigger apoptosis through caspase-dependent pathways in HL60 human promyelocytic leukemia (35) and HeLa human cervical cancer cells (36). In the present study, shikonin increased the activity of caspases-3, -8 and -9 , as well as the gene expression of caspase-3. Regulation of gene expression is important in directing apoptosis (37). The present study demonstrated that shikonin treatment affects the gene expression of apoptosis-associated proteins, including the downregulation of Bcl-2 and upregulation of Bax, p53 and caspase-3. These results are in agreement with those of previous studies indicating that shikonin treatment downregulates the expression of Bcl-2 and stimulates the activation of pro-caspase- 3 to caspase-3 (38).

In conclusion, the present study demonstrated that shikonin suppresses the growth of SMMC-7721 human hepatocellular carcinoma cells by inhibiting DNA synthesis, increasing ROS generation, triggering mitochondrial dysfunction, interfering with calcium homeostasis and altering apoptosis-associated gene expression. The present study supports the potential of shikonin as an efficient anti-cancer drug. Further study on hepatocellular carcinoma will contribute to the development of more effective and sophisticated treatment strategies.

\section{Acknowledgements}

This study was supported by the Natural Science Foundation of Liaoning Province (grant nos. 2014022042 and 201602325) and the Agricultural Science and Technology Innovation Program (grant no. cxgc-ias-01). The authors would like to thank Editage for providing the English language service.

\section{References}

1. Gong K and Li W: Shikonin, a Chinese plant-derived naphthoquinone, induces apoptosis in hepatocellular carcinoma cells through reactive oxygen species: A potential new treatment for hepatocellular carcinoma. Free Radic Biol Med 51: 2259-2271, 2011.

2. Brown JM and Attardi LD: The role of apoptosis in cancer development and treatment response. Nat Rev Cancer 5: 231-237, 2005. 
3. Chen X, Yang L, Zhang N, Turpin JA, Buckheit RW, Osterling C Oppenheim JJ and Howard OMZ: Shikonin, a component of Chinese herbal medicine, inhibits chemokine receptor function and suppresses human immunodeficiency virus type 1 . Antimicrob Agents Chemother 47: 2810-2816, 2003.

4. Hsu PC, Huang YT, Tsai ML, Wang YJ, Lin JK and Pan MH: Induction of apoptosis by shikonin through coordinative modulation of the Bcl-2 family, p27, and p53, release of cytochrome c, and sequential activation of caspases in human colorectal carcinoma cells. J Agric Food Chem 52: 6330-6337, 2004.

5. Min R, Tong J, Wenjun Y, Wenhu D, Xiaojian Z, Jiacai H, Jian Z, Wantao C and Chenping Z: Growth inhibition and induction of apoptosis in human oral squamous cell carcinoma Tca-8113 cell lines by shikonin was partly through the inactivation of NF-kappaB pathway. Phytother Res 22: 407-415, 2008.

6. Liu C, Yin L, Chen J and Chen J: The apoptotic effect of shikonin on human papillary thyroid carcinoma cells through mitochondrial pathway. Tumour Biol 35: 1791-1798, 2014.

7. Wang Y, Zhou Y, Jia G, Han B, Liu J, Teng Y, Lv J, Song Z, Li Y, Ji L, et al: Shikonin suppresses tumor growth and synergizes with gemcitabine in a pancreatic cancer xenograft model: Involvement of NF- $\kappa \mathrm{B}$ signaling pathway. Biochem Pharmacol 88: 322-333, 2014.

8. Mao X, Yu CR, Li WH and Li WX: Induction of apoptosis by shikonin through a ROS/JNK-mediated process in Bcr/Abl-positive chronic myelogenous leukemia (CML) cells. Cell Res 18: 879-888, 2008.

9. Duan D, Zhang B, Yao J, Liu Y and Fang J: Shikonin targets cytosolic thioredoxin reductase to induce ROS-mediated apoptosis in human promyelocytic leukemia HL-60 cells. Free Radic Biol Med 70: 182-193, 2014.

10. Jang SY, Hong D, Jeong SY and Kim JH: Shikonin causes apoptosis by up-regulating p73 and down-regulating ICBP90 in human cancer cells. Biochem Biophys Res Commun 465: 71-76, 2015.

11. Wiench B, Eichhorn T, Paulsen M and Efferth T: Shikonin directly targets mitochondria and causes mitochondrial dysfunction in cancer cells. Evid Based Complement Alternat Med 2012: 726025,2012

12. Li W, Liu J and Zhao Y: PKM2 inhibitor shikonin suppresses TPA-induced mitochondrial malfunction and proliferation of skin epidermal JB6 cells. Mol Carcinog 53: 403-412, 2014

13. Wang YW, Wang SJ, Zhou YN, Pan SH and Sun B: Escin augments the efficacy of gemcitabine through down-regulation of nuclear factor- $\mathrm{kB}$ and nuclear factor- $\mathrm{kB}$-regulated gene products in pancreatic cancer both in vitro and in vivo. J Cancer Res Clin Oncol 138: 785-797, 2012

14. Wang H, Yu Y, Li J, Wu H, Sun J, Zhang Z, Geng L, Yu X and Liu Z: Cadmium stimulates mouse skin fibroblast apoptosis by affecting intracellular homeostasis. Drug Chem Toxicol 40 : 74-84, 2017.

15. Young MM, Takahashi Y, Khan O, Park S, Hori T, Yun J, Sharma AK, Amin S, Hu CD, Zhang J, et al: Autophagosomal membrane serves as platform for intracellular death-inducing signaling complex (iDISC)-mediated caspase- 8 activation and apoptosis. J Biol Chem 287: 12455-12468, 2012.

16. Schmittgen TD and Livak KJ: Analyzing real-time PCR data by the comparative C(T) method. Nat Protoc 3: 1101-1108, 2008.

17. Li Y, Ahmed F, Ali S, Philip PA, Kucuk O and Sarkar FH Inactivation of nuclear factor kappaB by soy isoflavone genistein contributes to increased apoptosis induced by chemotherapeutic agents in human cancer cells. Cancer Res 65: 6934-6942, 2005.

18. Wang H, Wu C, Wan S, Zhang H, Zhou S and Liu G: Shikonin attenuates lung cancer cell adhesion to extracellular matrix and metastasis by inhibiting integrin $\beta 1$ expression and the ERK1/2 signaling pathway. Toxicology 308: 104-112, 2013.

19. Wu Z, Wu L, Li L, Tashiro S, Onodera S and Ikejima $\mathrm{T}$ : p53-mediated cell cycle arrest and apoptosis induced by shikonin via a caspase-9-dependent mechanism in human malignan melanoma A375-S2 cells. J Pharmacol Sci 94: 166-176, 2004.

20. Han W, Xie J, Li L, Liu Z and Hu X: Necrostatin-1 reverts shikonin-induced necroptosis to apoptosis. Apoptosis 14: 674-686, 2009.
21. Gong K, Zhang Z, Chen Y, Shu HB and Li W: Extracellular signal-regulated kinase, receptor interacting protein, and reactive oxygen species regulate shikonin-induced autophagy in human hepatocellular carcinoma. Eur J Pharmacol 738: 142-152, 2014.

22. Yeh CC, Kuo HM, Li TM, Lin JP, Yu FS, Lu HF, Chung JG and Yang JS: Shikonin-induced apoptosis involves caspase-3 activity in a human bladder cancer cell line (T24). In Vivo 21: 1011-1019, 2007.

23. Chen C, Shanmugasundaram K, Rigby AC and Kung AL: Shikonin, a natural product from the root of Lithospermum erythrorhizon, is a cytotoxic DNA-binding agent. Eur J Pharm Sci 49: 18-26, 2003.

24. Jo SK, Hong JY, Park HJ and Lee SK: Anticancer activity of novel daphnane diterpenoids from daphne genkwa through cell-cycle arrest and suppression of Akt/STAT/Src signalings in human lung cancer cells. Biomol Ther (Seoul) 20: 513-519, 2012.

25. Wang BF, Dai ZJ, Wang XJ, Bai MH, Lin S, Ma HB, Wang YL, Song LQ, Ma XL, Zan Y, et al: Saikosaponin-d increases the radiosensitivity of smmc-7721 hepatocellular carcinoma cells by adjusting the $\mathrm{g} 0 / \mathrm{g} 1$ and $\mathrm{g} 2 / \mathrm{m}$ checkpoints of the cell cycle. BMC Complement Altern Med 13: 263, 2013.

26. Liu J, Wang P, Xue YX, Li Z, Qu CB and Liu YH: Enhanced antitumor effect of shikonin by inhibiting endoplasmic reticulum stress via JNK/c-Jun pathway in human glioblastoma stem cells. Biochem Biophys Res Commun 466: 103-110, 2015.

27. Lee MJ, Kao SH, Hunag JE, Sheu GT, Yeh CW, Hseu YC, Wang CJ and Hsu LS: Shikonin time-dependently induced necrosis or apoptosis in gastric cancer cells via generation of reactive oxygen species. Chem Biol Interact 211: 44-53, 2014.

28. Chen CH, Chern CL, Lin CC, Lu FJ, Shih MK, Hsieh PY and Liu TZ: Involvement of reactive oxygen species, but not mitochondrial permeability transition in the apoptotic induction of human SK-Hep-1 hepatoma cells by shikonin. Planta Med 69: $1119-1124,2003$

29. Yingkun N, Lvsong $Z$ and Huimin Y: Shikonin inhibits the proliferation and induces the apoptosis of human HepG2 cells. Can J Physiol Pharmacol 88: 1138-1146, 2010.

30. Chang IC, Huang YJ, Chiang TI, Yeh CW and Hsu LS: Shikonin induces apoptosis through reactive oxygen species/extracellular signal-regulated kinase pathway in osteosarcoma cells. Biol Pharm Bull 33: 816-824, 2010.

31. Breckenridge DG, Stojanovic M, Marcellus RC and Shore GC: Caspase cleavage product of BAP31 induces mitochondrial fission through endoplasmic reticulum calcium signals, enhancing cytochrome $\mathrm{c}$ release to the cytosol. J Cell Biol 160: 1115-1127, 2003.

32. Desagher S and Martinou JC: Mitochondria as the central control point of apoptosis. Trends Cell Biol 10: 369-377, 2000

33. Hengartner MO: The biochemistry of apoptosis. Nature 407: $770-776,2000$

34. Urrego D, Tomczak AP, Zahed F, Stühmer W and Pardo LA: Potassium channels in cell cycle and cell proliferation. Philos Trans R Soc Lond B Biol Sci 369: 20130094, 2014.

35. Yoon Y, Kim YO, Lim NY, Jeon WK and Sung HJ: Shikonin, an ingredient of Lithospermum erythrorhizon induced apoptosis in HL60 human premyelocytic leukemia cell line. Planta Med 65: $532-535,1999$.

36. Wu Z, Wu LJ, Li LH, Tashiro SI, Onodera S and Ikejima T: Shikonin regulates HeLa cell death via caspase-3 activation and blockage of DNA synthesis. J Asian Nat Prod Res 6: 155-166, 2004.

37. Fink SL and Cookson BT: Apoptosis, pyroptosis, and necrosis: Mechanistic description of dead and dying eukaryotic cells. Infect Immun 73: 1907-1916, 2005.

38. Xie Y, Fan C, Dong Y, Lynam E, Leavesley DI, Li K, Su Y, Yang Y and Upton Z: Functional and mechanistic investigation of shikonin in scarring. Chem Biol Interact 228: 18-27, 2015.

This work is licensed under a Creative Commons

Attribution-NonCommercial-NoDerivatives 4.0 International (CC BY-NC-ND 4.0) License. 